\title{
EL ENFOQUE RELACIONAL COMO METODOLOGÍA DE ANÁLISIS EN EL DERECHO DEL TRABAJO: EL EXPEDIENTE DE INCLUSIÓN FRENTE A LA DISCRIMINACIÓN LABORAL $^{1}$
}

The relational approach as a methodology of analysis in Labour law: the inclusion record against labour discrimination

Recibido: 16 de noviembre de 2019

Aceptado: 20 de diciembre de 2019

José Luis Ruiz Santamaría²

Departamento de Derecho del Trabajo y Seguridad Social

jlrsantamaria@uma.es

Universidad de Málaga

\section{RESUMEN}

Este trabajo, tras indagar inicialmente sobre la idea de la justicia social y su repercusión en las relaciones de trabajo, centraremos nuestro interés en la aplicación del enfoque de justicia relacional, como métodología de análisis que, aplicada en el contexto específico del Derecho del trabajo, se muestra como una herramienta muy útil que favorece su comprensión y alcance. En su configuración destacan tres dimensiones: reciprocidad, institucionalidad y socialidad. Desde esta triple perspectiva, y superando el análisis unidimensional basado exclusivamente en la aplicación estricta de la norma jurídica -institucionalidad-, se considera fundamental la dimensión del trato $\mathrm{o}$ comportamiento recíproco -reciprocidad-, así como, el respeto a determinados valores que fortalecen la confianza en las relaciones laborales -socialidad-. Especial atención merece el estudio de aquellas situaciones de desigualdad y/o discriminación, de determinados colectivos de personas trabajadoras que, por diversas razones (discapacidad, edad, sexo, etc.), sufren con respecto al resto de los trabajadores. Por este motivo, debe advertirse acerca de la necesidad de una inclusión eficaz y efectiva en las relaciones de trabajo, lo que implica la integración en la relación de interdependencia, en condiciones de simetría social -expediente de inclusión-.

\section{PALABRAS CLAVE:}

Enfoque relacional, Derecho del trabajo, reciprocidad, socialidad, discriminación.

\footnotetext{
${ }^{1}$ Este trabajo está enmarcado en lo Grupos de Investigación: PAIDI SEJ-347 sobre "Políticas de empleo, igualdad e inclusión social", FRATERNI-LAB SMART UMA y en la RED TEMÁTICA INTERNACIONAL DE JUSTICIA RELACIONAL Y ECOLOGÍA INTEGRAL (JUR-EI).

${ }^{2}$ Profesor SI Doctor de Derecho del Trabajo y Seguridad Social de la Universidad de Málaga. ORCID ID.: 00000002-9814-4429.
} 


\section{ABSTRACT}

In this paper, after initially inquiring about the idea of social justice and its impact on labor relations, we will focus our interest in the application of the relational justice approach, as an analysis methodology that, applied in the specific context of Labor Law, is shown as a very useful tool that favors its understanding and scope. In its configuration three dimensions stand out: reciprocity, institutionality and sociality. From this triple perspective, and surpassing the one-dimensional analysis based exclusively on the strict application of the legal norm -institutionality-, the dimension of the reciprocal treatment or behavior -reciprocity- is considered fundamental, as well as the respect for certain values that strengthen trust in labor relations -sociality-. Special attention deserves the study of situations of inequality and / or discrimination, of certain groups of working people who, for various reasons - disability, age, sex, etc. - suffer from the rest of the workers. For this reason, it should be noted about the need for efficient and effective inclusion in labor relations, which implies integration into the interdependence relationship, under conditions of social symmetry -inclusion record-.

\section{KEYWORDS:}

The relational approach, Labour law, reciprocity, sociality, discrimination. 
Sumario: 1. Cuestiones preliminares: el carácter interdisciplinar del enfoque relacional. 2. Las aportaciones de Antonio Genovesi y su influencia en España. 3. Aproximación conceptual al enfoque de justicia relacional. 4. Vacíos de justicia. 5. Expediente de inclusión. 6. Conclusiones. Bibliografía.

\section{Cuestiones preliminares: el carácter interdisciplinar del enfoque relacional.}

El reciente interés mostrado sobre la idea de la justicia social y sus implicaciones prácticas en las relaciones de trabajo, va a determinar el inicio de una serie de investigaciones ${ }^{3}$ partiendo de una concepción previa de justicia que se va a traducir en la aplicación al Derecho del enfoque relacional propio de la Sociología. En dichos estudios, que se abordan en un contexto interdisciplinar, experimentan un especial protagonismo, la Sociología, la Economía, la Filosofía, e incluso la Teoría de juegos, como área propia de la Matemática aplicada, en relación continua y directa con el Derecho. Desde este planteamiento, se pone de manifiesto por parte del profesor MÁRQUEZ PRIETO que "la aplicación del enfoque relacional a la idea de justicia produce como efecto que el Derecho del Trabajo, rama del ordenamiento jurídico particularmente orientada desde sus orígenes a la justicia social, se revela como experiencia capaz de ser comprendida de forma más amplia y simple, como adaptación jurídica (...) a las sugerencias, necesidades, y explicaciones de sentido desde la realidad social, en aras de una justicia relacional"4.

Consecuentemente, y como contribución necesaria a una mejor comprensión del fenómeno, se hace indispensable realizar una aproximación a aquellos autores más representativos e influyentes, que perteneciendo a estas diferentes áreas disciplinares, han favorecido de forma eficaz, mediante sus aportaciones doctrinales, la construcción y el diseño del enfoque teórico de justicia relacional.

En el área de la Sociología, se destacan como influencias más notables: en primer lugar, las aportadas por Pierpaolo DONATI, de la Universidad de Bolonia (Italia), autor del libro Repensar la sociedad ; y por otra parte, en España, las del profesor Pablo

\footnotetext{
${ }^{3}$ Nos referimos concretamente a los trabajos de investigación iniciados, hace más de una década, por el profesor Antonio MÁRQUEZ PRIETO de la Universidad de Málaga, y que han dado lugar a los siguientes grupos de investigación: RED INTERNACIONAL DE ESTUDIOS INTERDISCIPLINARES SOBRE JUSTICIA RELACIONAL (RIF), RED TEMÁTICA INTERNACIONAL DE JUSTICIA RELACIONAL Y ECOLOGÍA INTEGRAL (JUR-EI) y FRATERNI-LAB SMART UMA. Los integrantes de dichos equipos son expertos en distinta disciplinas del Derecho, o en otras ramas de las Ciencias Sociales (Economía, Filosofía, Ciencia Política y Psicología). La mayoría son investigadores de la Universidad de Málaga, junto con otros pertenecientes al Instituto Universitario Sophia (Florencia), Universidad Autónoma de Barcelona, Universidad Internacional de Cataluña y Montclair Setate University (Nueva Jersey). Para mayor profundización véase en MÁRQUEZ PRIETO, A. (2017): "Una investigación en equipo sobre justicia relacional y principio de fraternidad”, en MÁRQUEZ PRIETO, A. (Coord.) Justicia relacional y principio de fraternidad, Cizur Menor (Navarra): Aranzadi - Thomson Reuters, págs. 17-28.

${ }^{4}$ Vid. MÁRQUEZ PRIETO, A. (2008): Repensar la justicia social. Enfoque relacional, teoría de juegos y relaciones laborales en la empresa, Cizur Menor (Navarra): Aranzadi - Thomson Reuters, 2008, pág. 11.

${ }^{5}$ Vid. DONATI, P. (2006): Repensar la sociedad, Madrid: Ediciones Internacionales Universitarias. Esta obra ha sido traducida al español y acompañada de un estudio introductorio por el profesor de la Universidad de Navarra, Pablo GARCÍA RUIZ. Otras obras de este autor son: - (1986): Introduzione alla sociología relazionale, Milán (Italia): Franco Angeli ( $2^{\mathrm{a}}$ ed.); - (2002): “Ciudadanía y Sociedad Civil: dos paradigmas (ciudadanía lib/lab y ciudadanía societaria)”, Reis, núm. 98, págs. 37-64; - (2005): "Quale conciliazione tra familia e laboro? La prospettiva relazionale", en DONATI, P., Famiglia e lavoro: dal conflitto a nuove sinergie, Milán (Italia): Franco Angeli; - (2013): Sociologia relazionale. Come cambiare la società, Brescia (Italia): Editrice La Scuola. También, y sobre este tema, puede consultarse en DONATI,
} 
GACÍA RUIZ, de la Universidad de Navarra, traductor de la obra de DONATI al español y autor de un elaborado e ilustrativo estudio introductorio. Sobre estos autores, hay que destacar que el profesor DONATI es el fundador del enfoque de la "Sociología relacional" que fue introducida en España por GARCÍA RUIZ, erigido como el máximo representante de dicha corriente doctrinal en nuestro país ${ }^{6}$.

En el ámbito jurídico-filosófico, ha supuesto una importante contribución la "Teoría de las constituciones civiles", de Günter TEUBNER, profesor de Derecho Privado y de Sociología del Derecho, en la Universidad de Frankfurt (Alemania). Su construcción jurídico-filosófica ${ }^{7}$ ha resultado ser muy útil a la hora de determinar la "constitucionalización" de las relaciones socio-laborales en la empresa ${ }^{8}$.

Otras fuentes doctrinales, que han protagonizado una influencia muy destacada en la formación conceptual de las ideas que integran el enfoque de justicia relacional, son las que se producen en el área de la Economía. La primera aportación es la que ha tenido lugar a cargo de Luigino BRUNI. Su obra titulada Reciprocit $\grave{a}^{9}$ es un aporte de enorme valor, a la hora de realizar el engarce de las estrategias de reciprocidad en el conjunto de la idea de justicia que se propone en la óptica de la justicia relacional. El citado profesor, “(...) logra demostrar, sirviéndose de la Teoría de juegos, que las distintas dinámicas de reciprocidad, desde las motivadas exclusivamente por el interés propio hasta las que favorecen el interés común, producen un efecto conjunto benéfico para la comunidad en la medida en que las distintas mecánicas aparecen mezcladas con suficiente heterogeneidad y pluralismo"10. Además, añade, que este mismo autor en su obra Le nuove virtú del mercato nell'era dei beni comuni ${ }^{11}$ "(...) alude a la justicia relacional, como categoría concreta de justicia, como nota presente -o ausente- en la relación

P. y CALVO, P. (2014): "New Insights into Relational Goods", Recrea. Revista de Pensament i Anàlisi, núm. 14, págs. 7-17.

${ }^{6} \mathrm{Vid}$. MÁRQUEZ PRIETO, A. (2008): Repensar la justicia social... op. cit., págs. 11-13.

7 Vid. TEUBNER, G. (2005): La cultura del diritto nell'epoca della globalizzazione. L'emergere delle constituzioni civilli, Roma (Italia): Armando Editore, passim.

${ }^{8}$ Vid. MÁRQUEZ PRIETO, A. (2008): Repensar la justicia social... op. cit., pág. 14.

${ }^{9} \mathrm{Vid}$. BRUNI, L. (2006): Reciprocità. Dinamiche di cooperazione, economia e società civile, Milán (Italia): Bruno Mondadori, passim.

${ }^{10}$ Queremos destacar, como hecho novedoso que se incorpora en la obra Reciprocità de BRUNI, la demostración que realiza este autor -apoyándose en el lenguaje matemático- de la reciprocidad como efecto de dinámicas interpersonales muy distintas -la fraternidad en la diversidad-, constituyéndose en este sentido como una propuesta realista y eficiente -alejándose por tanto del posible tinte utópico que desde la crítica científica pudiera atribuirse-. También, debemos resaltar que se trata de un paradigma universal, superando en este sentido el ámbito exclusivo de la Economía, para abarcar otros, especialmente el que corresponde al jurídico en términos muy similares a la propuesta que, desde la perspectiva de la Sociología, han ofrecido DONATI Y GARCÍA RUIZ. Vid. MÁRQUEZ PRIETO, A. (2008): Repensar la justicia social... op. cit., pág. 13. Así mismo, otras obras del profesor BRUNI que merecen ser destacadas son: BRUNI, L. (2005): "Hic Sunt Leones: Social Relations As Unexplored Territory in the Economic Tradition", en GUY, B. y SUGDEN, R. (eds.) Economics and Social Interactions, Cambridge (Reino Unido): Cambridge University Press; - (2006): Civil Hapiness: Economics and Human Flourishing in Historical Perpective, Londres (Reino Unido) y Nueva York (Estados Unidos): Routledge; - (2010): L'ethos dell merecato. Un'introduzione ai fondamenti antropologici dell'economia, Milán-Turín (Italia): Bruno Mondadori; - Le nuove virtù del mercato nell'era dei beni comuni, Roma (Italia): Città Nuova, y BRUNI, L. y ZAMAGNI, S. (2013): "Introduzione", en GENOVESI, A. Lezioni di economía civile, Milán (Italia): Vita e Pensiero, Francesca Dal Degan, págs. VII-XXII.

${ }^{11}$ Vid. BRUNI, L. (2012): Le nuove virtù del mercato nell'era dei beni comuni, Roma (Italia): Città Nuova, passim. 
jurídica, y como explicación del cierre del círculo virtuoso de la justicia -o, por el contrario, el círculo vicioso de la injusticia- en la relación"12.

Otras aportaciones de la ciencia económica que corresponden al retorno reciente de la preocupación en Economía por "lo común" 13 han sido llevadas a cabo por el profesor austriaco de economía Christian FELBER, en su libro La economía del bien común ${ }^{14} \mathrm{y}$ por el economista italiano Stefano ZAMAGNI, en su obra Por una economía del bien común $n^{15}$. Este autor italiano ${ }^{16}$ hace referencia a los tres principios reguladores del mercado: el primero, la división del trabajo; el segundo, la noción de desarrollo, que lleva a la acumulación; y el tercero, que hace referencia a la libertad de empresa. Junto a estos principios, este autor añade un cuarto principio, especificando que: "Este puede ser el bien común o el bien total. En el primer caso se hablará de economía de mercado civil; en el segundo caso, de economía de mercado capitalista. La ética de las virtudes es básicamente la ética del bien común. Es el hecho de que los intercambios tengan lugar en un contexto de redes de solidaridad, es decir en el interior de una comunidad, lo que legitima la actividad de mercado. Podemos intercambiar, con ventaja mutua, porque antes de cualquier otra cosa estamos unidos por una obligatio, por un ligamen que hace que el intercambio siga siendo civil. En buena sustancia, para la ética de las virtudes, es la lógica de la reciprocidad la que preserva el mercado de sus degeneraciones"17.

También, debemos añadir como singularidad destacable de ZAMAGNI ${ }^{18}$, la magistral explicación que hace en su artículo "Bene comune e fraternità. Il contributo italiano alla storia del Pensiero" sobre la diferencia existente entre bien común y bien total, expresándolo este autor en los siguientes términos: "Mientras el bien total puede ser representado por la imagen de un sumatorio, en el que los sumandos representan el bien de los sujetos, el bien común es asimilable más propiamente a un producto, en el que los factores representan el bien de los sujetos. Es claro el sentido de la metáfora: en una suma, si se anula alguno de los sumandos, la suma total sigue siendo en todo caso positiva. Incluso, puede suceder que si el objetivo es maximizar el bien total convenga 'anular' el bien -o bienestar- de alguno a condición de que la ganancia de bienestar de algún otro aumente en medida suficiente para la compensación. No es así, por el contrario, en el caso del producto, porque la anulación de uno solo de los factores convierte en cero el producto entero. Dicho en otros términos, la del bien común es una lógica que no admite sustituibilidad: no se puede sacrificar el bien de alguno -cualquiera que sea su situación

\footnotetext{
12 Vid. MÁRQUEZ PRIETO, A. (2014): “La Justicia Relacional como círculo virtuoso”, Recrea, Revista de Pensament i Anàlisi, núm. 14, pág. 117.

${ }^{13}$ Respecto a esta reciente preocupación en la Economía por "lo común” se establece que “(...) se suele relacionar con la llamada de alarma que supuso la publicación del artículo "La tragedia de los comunes" en 1968, por parte de Garret HARDIN. Este a su vez aludía a un escenario descrito por William Foster LLOYD en el libro Two Lectures on the Checks to Populations (Oxford University, 1933). El escenario descrito por LLOYD es un prado de uso compartido por varios pastores que permite, de forma prudente, un número limitado de animales. Sin embargo, el aumento, por parte de cada uno de los pastores, de los animales llevados a pastar -es decir, un comportamiento irresponsable e individual de cada uno de ellos- provoca que mueran de hambre tanto los rebaños como los pastores, por la sobreexplotación del pastizal". Vid. MÁRQUEZ PRIETO, A. (2015): "La relación laboral como relación social (justicia relacional y socialidad común)", Revista Centro de Estudios Financieros, núm. 382, pág.16.

${ }^{14}$ Vid. FELBER, C. (2012): La economía del bien común, Bilbao: Deusto, passim.

15 Vid. ZAMAGNI, S. (2012): Por una economía del bien común, Madrid: Ciudad Nueva, passim.

${ }^{16}$ Ibídem., págs. 17-33.

${ }^{17}$ Vid. ZAMAGNI, S. (2012): "Bene comune e fraternità. Il contributo italiano alla storia del Pensiero", en Treccani.it. L'enciclopedia italiana. Economía: págs. 5-9. Disponible en: http://www.treccani.it.

$18 \mathrm{Y}$ así lo ha destacado MÁRQUEZ PRIETO en su artículo: "La relación laboral como relación social (justicia relacional y socialidad común)”...op. cit., pág. 17.
} 
de vida o su configuración social- para mejorar el bien de algún otro y ello por la razón fundamental de que ese alguno es siempre un portador de derechos humanos fundamentales. Para la lógica del bien total, por el contrario, ese alguno es un individuo, es decir, un sujeto identificado por una particular función de utilidad y las utilidades como es sabido- se pueden tranquilamente sumar -y confrontar-, porque no tienen rostro, no expresan una identidad, ni una historia. Siendo común, el bien común no mira a la persona tomada en su singularidad, sino en cuanto está en relación con otras personas; es el bien propio de la vida en común. Es común lo que no es solo propio -así sucede en cambio con el bien privado- y lo que no es de todos indistintamente -así sucede con el bien público"19.

En definitiva, adviértase que aquellos sujetos que tengan asignado el valor "cero" en relación al bien que le corresponda, desde la perspectiva del bien total -y en la medida que actúa bajo la fórmula del sumatorio-, el resultado final no sufrirá ninguna alteración y seguirá siendo positivo. Sin embargo, esta misma situación, desde la óptica del bien común -que actúa como un producto-, el resultado final se verá afectado, computándose el mismo como nulo.

\section{Las aportaciones de Antonio Genovesi y su influencia en España.}

Otra referencia doctrinal que conviene señalar, por la importante influencia que va a ejercer en la actual escuela italiana de Economía civil, es la que se produce a cargo del economista napolitano del siglo XVIII Antonio GENOVESI. Este autor, que fue contemporáneo de Adam SMITH ${ }^{20}$, compartió la crítica del mundo feudal y la creencia de que el mercado contribuiría a la construcción de un mundo más igualitario y más libre. Pero mientras SMITH tenía una visión pesimista del hombre basada en el individualismo de intereses y, consecuentemente, el bien común se confiaba y dependía de la "mano

\footnotetext{
${ }^{19}$ Ibídem., págs. 10-11.

${ }^{20}$ Es importante resaltar que Adam SMITH fue el fundador del movimiento denominado el liberalismo económico; y al mismo tiempo, considerado el padre de los economistas clásicos. De su producción científica, destacaremos dos obras por el importante impacto y acogida que tuvieron en su época, y que aun hoy se sigue haciendo referencia a las mismas. La primera de ellas es The Theory of Moral Sentiments [Teoría de los sentimientos morales, Londres (1759)] que es un tratado sobre ética, en el que se exploran todas las conductas humanas en las que el egoísmo no parece jugar un papel determinante -manteniendo en este sentido una tesis diferente a Thomas HOBBES-. SMITH realiza una propuesta consistente en adoptar un proceso de empatía a través del cual una persona podrá situarse en el lugar de la otra, aun cuando no obtenga beneficio de ello. La segunda obra que merece su mención es The Wealth of Nations [La riqueza de las naciones, Londres (1776)], obra en la que sostiene que la riqueza procede del trabajo, tratándose esencialmente de un estudio en el que se aborda el proceso de creación y acumulación de la riqueza. En general, SMITH desarrolló y elaboró un nuevo modelo social que fuera comprensible e inspirara confianza, a la vez que pudiera servir para mejorar la calidad de vida de las personas. También estudió la estructura de la sociedad moderna en su totalidad, su marco legal, su moral, sus creencias, su modo de distribución del trabajo y su forma de intercambio. Por otra parte, pensaba que el hombre es esencialmente un ser histórico y social y se propuso investigar y comprender el resultado de las relaciones sociales para poder construir bases firmes para su reforma. En relación a las referencias bibliográficas de las obras comentadas de este autor, puede consultarse -en inglés- las siguientes ediciones: SMITH, A. (2008): An Inquiry into the Nature and Causes of The Wealth of Nations: A Selected Edition, en SUTHERLAND, K (ed.). Oxford (Reino Unido): Oxford Paperbacks; y también véase, SMITH, A. (2002): The Theory of Moral Sentiments ( $1^{a}$ ed. 1759), Cambridge (Reino Unido): Cambridge University Press. Para profundizar en los aspectos biográficos de este autor, puede consultarse en HEILBRONER, R. (S/F): Adam Smith. Scottish Philosopher, en Encyclopaedia Britannica. Disponible en: https://www.britannica.com/biography/AdamSmith.
} 
invisible" ${ }^{21}$ del mercado; por el contrario, GENOVESI, en sus Lezioni di economia civile [Lecciones de economía civil] ${ }^{22}$ sostiene que la persona es el equilibrio de dos fuerzas: las de interés para yo y la solidaridad social; el sujeto aparece como una realidad relacional hecha para la reciprocidad. De ahí su idea del mercado como "asistencia mutua" 23 . A pesar de que fueron las ideas de Adam SMITH las que calaron con gran aceptación en la sociedad de aquella época; no se puede obviar que la concepción de la economía por GENOVESI fuera también una referencia a seguir, aunque de forma localizada y minoritaria. Un ejemplo de esta influencia del economista napolitano va a tener lugar en España a cargo del jurista valenciano Bernardo Joaquín DANVILA y VILLARRASA $^{24}$. Este hito histórico -poco conocido, por no haber tenido mucha difusión, en la medida que fueron las ideas de Adam SMITH las que gozaron de una aceptación con mayor calado- se materializa con la publicación, en 1779, de las Lecciones de Economía Civil, o de el Comercio ${ }^{25}$ [sic], elaboradas por este autor.

Pablo CERVERA FERRI, autor del estudio introductorio ${ }^{26} \mathrm{y}$ de los comentarios que acompañan la obra citada, destaca de la misma, entre otras apreciaciones, que fue la referencia bibliográfica para instruir a los jóvenes candidatos a la administración real del Seminario de Nobles de Madrid. Cinco años después, estas Lecciones fueron escogidas como manual para la primera cátedra de Economía política en España e impartidas en las recién estrenadas aulas de la Real Sociedad Económica Aragonesa de Amigos del País.

21 "The invisible hand" [La mano invisible] es una metáfora que expresa en economía la capacidad autorreguladora del libre mercado. Introducida por Adam SMITH en su obra The Theory of Moral Sentiments [Teoría de los sentimientos morales (1759)], pero popularizada gracias a su obra: The Wealth of Nations [La riqueza de las naciones (1776)], a pesar de que solo fue utilizada una vez en este último texto. Con esta expresión, su autor pretendía no solo asignar las tareas, sino que también dirigir a las personas en la elección de su ocupación y hacer que se tenga en cuenta las necesidades de la sociedad. De la misma manera, el mercado regula cuales son las mercancías que han de producirse. SMITH, A. (2008): An Inquiry into the Nature and Causes of the Wealth of Nations: A Selected Edition...op. cit., passsim y en SMITH, A. (2002): The Theory of Moral Sentiments ( $1^{a}$ ed. 1759)... op. cit., passsim.

${ }^{22}$ Vid. GENOVESI, A. (2013): Lezioni di economia civile, Milán (Italia): Vita e Pensiero, Francesca Dal Degan, passim.

${ }^{23}$ En este sentido, Luigino BRUNI y Stefano ZAMAGNI -coautores de la "Introduzione" de la versión publicada en 2013, de Lezioni di economia civile de Antonio GENOVESI- han señalado que, en la actualidad, la idea del mercado como "asistencia mutua" es una intuición original que está experimentando una nueva juventud. También han destacado que "GENOVESI puede ser considerado, con razón, uno de los fundadores de la ciencia económica moderna. Este autor napolitano comenzó a ocuparse casi exclusivamente de la economía, la ética y la antropología solo en los últimos quince años de su vida. Fue el primero en Europa en ocupar una cátedra de Economía -establecida en Nápoles en 1754-, pudo difundir su magisterio no solo en Italia sino en todo el contexto de la Ilustración". Añaden que "Las Lecciones de comercio o economía civil son el corpus del curso universitario llevado a cabo por este autor, pero sobre todo contienen la suma de su reflexión sobre cuestiones económicas". Vid. BRUNI, L. y ZAMAGNI, S. (2013): "Introduzione", en GENOVESI, A. (2013): Lezioni di economia civile. Milán (Italia): Vita e Pensiero, Francesca Dal Degan, págs. VII-XXII.

${ }^{24}$ Este autor fue un destacado jurista, economista y filósofo que nació en Valencia en 1740 y falleció en Madrid en1787. Cursó Filosofía en la Universidad de Valencia en 1760. Años más tarde, en 1767, alcanzaría el doctorado en Jurisprudencia y Derecho Canónico. En 1775 se traslada a Madrid para habilitarse como abogado de los Reales consejos y opositó a las cátedras de Griego, Cánones, Instituciones y Código. También, en ese mismo año accedería a la cátedra de Filosofía Moral y Derecho Natural y de Gentes, que ejerció en el prestigioso Real Seminario de Nobles de la Villa. Vid. CERVERA FERRI, P. (S/F): "Bernardo Joaquín Danvila y Villarrasa", en VV. AA. Real Academia de la Historia. DBE, págs. s/n.Disponible en: http://dbe.rah.es/biografias/21094/bernardo-joaquin-danvila-y-villarrasa.

${ }^{25}$ Vid. DANVILA Y VILLARRASA, B. J. (2008): Lecciones de Economía Civil o de el Comercio. Estudio introductorio y edición anotada por Pablo Cervera Ferri (MDCCLXXIX), Zaragoza: Institución "Fernando el Católico"- Biblioteca Ernest Lluch de Economistas Aragoneses 10.

${ }^{26}$ Ibídem., págs., 11-76. 
El mérito de esta obra es aún mayor si la contemplamos en su calidad de introductora de algunas de las más avanzadas propuestas de la Europa ilustrada para comprender la naturaleza del valor, la formación de los precios, la generación de la riqueza y su circulación. La adaptación de pasajes del Essai sur la nature du commerce en général del franco-irlandés Richard CANTILLON (1755), y de los textos fundamentales de Antonio GENOVESI (1765-1767) y del abad de CONDILLAC (1776), engarza a las Lecciones de DANVILA Y VILLARRASA como un importante eslabón en el complejo proceso de selección y de difusión de las ideas económicas en la España de las Luces. En relación a la estructura de las Lecciones de Economía Civil, o de el Comercio[sic], y tomando como referencia el excelente estudio que acompaña a esta obra a cargo de CERVERA FERRI, podemos apreciar que las Lecciones se dividen en siete capítulos, seguidos de un apéndice con noventa y nueve conclusiones. El prólogo integra a la Economía Civil en la Filosofía práctica y recoge influencias de ARISTÓTELES y HEINECCIO. La Lección I emplazaba a la agricultura en el origen de la propiedad y esbozaba una teoría histórica de cuatro estadios enraizada en el humanismo cristiano de MALEBRANCHE y de BOSSUET. La Lección II explicaba el valor y los precios con argumentos del Essai sur la nature du commerce en général de Richard CANTILLON (1755) y de Le commerce et le gouvernement de CONDILLAC (1776). El agrarismo de DANVILA se perfilaba en las Lecciones III y IV, donde introducía la clasificación de Antonio GENOVESI (17651767) entre las artes primitivas y secundarias, para concluir que la labranza genera todo el excedente destinado a la circulación económica. La Lección IV trataba sobre la industria. DANVILA criticaba el lujo y defendía la utilidad socioeconómica de los gremios desde una perspectiva algo más dúctil que la de Antonio CAPMANY. La desocupación, la caridad y la educación son el núcleo de la Lección V. La posición de DANVILA no fue, en estas materias, demasiado distante de las de Bernardo WARDO DE PÉREZ DE LARREA, y se refuerza con su experiencia directa con el Montepío de los Desamparados. La Lección VI trata el comercio y la VII amplía la teoría del valor con aportaciones sobre el interés de CANTILLON y con una reflexión propia, un tanto imprecisa, sobre la teoría cuantitativa del dinero.

\section{Aproximación conceptual al enfoque de justicia relacional.}

Analizados los autores más influyentes ${ }^{27}$, así como los elementos más característicos de las ideas impulsoras de sus teorías, corresponde ahora realizar una aproximación a los conceptos fundamentales que definen y configuran el enfoque de la justicia relacional. Nuestro primer paso estará orientado hacia, lo que se ha denominado "el porqué de la justicia relacional" 28; es decir, debemos indagar sobre la esencia misma del enfoque relacional, analizando el contenido -o vacío- de justicia existente en la relación interpersonal, en las diversas dimensiones de las relaciones sociales. Adviértase que la justificación de la razón de ser o el porqué de la justicia relacional, tiene su origen en la

\footnotetext{
${ }^{27}$ No debemos olvidar otros autores, cuyas aportaciones e influencias han contribuido de igual forma a la construcción del enfoque de justicia relacional. En esta línea, y como más representativos del siglo XX, citaremos a Jürgen HABERMAS y John RAWLS que, con sus obras, reflexiones y debates, en torno a la idea de la justicia, la crisis de la postmodernidad y la transformación del concepto, etc., han sido una referencia constante para los autores actuales. Véase al respecto las siguientes obras: HABERMAS, J. (2010): Facticidad y Validez (6 ${ }^{a}$ ed.), Madrid: Trotta editorial, págs. 570-580; idem (1998): Escritos sobre moralidad y eticidad. Barcelona: Paidós Ibérica, págs. 149-150; RAWLS, J. (1971): A theory of justice. Cambridge (Estados Unidos): Harvard University Press y VALLESPÍN, F. (1998): "Introducción. Una disputa de familia: el debate Rawls-Habermas", en HABERMAS, J. y RAWLS, J. Debate sobre el liberalismo político, Barcelona: Paidós, pág. 13.

${ }^{28}$ Vid. MÁRQUEZ PRIETO, A. (2008): Repensar la justicia social... op. cit., págs. 18-21.
} 
separación entre el Derecho y la idea de justicia, que va a suceder al finalizar la Edad Moderna. Por otra parte, este hito histórico, provocado por el desbordamiento de la idea moderna de justicia, va a requerir que para poder superar este problema se tenga que abordar esta nueva idea de justicia, no como fundamento, sino como resultado. En consecuencia, y de conformidad con los principios inspiradores del enfoque relacional, supone que "pensar en la justicia como un output o resultado exige encontrar un input adecuado, sin que el Derecho, como tal, esté en grado de jugar ese papel"29.

Por otra parte, no debemos obviar la "tentación del Derecho de suplantar a la justicia, con el argumento de la funcionalidad, de la eficiencia, y la necesidad del jurista de evitar esa trampa, saliendo en busca de la eficacia y de la justicia" 30 .

Al hilo de estas ideas, y como ya hemos tenido ocasión de expresar con anterioridad, ha resultado ser de gran utilidad, a la hora de elaborar y desarrollar el enfoque relacional que, desde el área de la Sociología, realizado por DONATI. Concretamente, este autor desarrolla la dinámica de la relación social en base a lo que él denomina "tres semánticas" que son: la referencial ${ }^{31}$, la estructural ${ }^{32}$ y la generativa ${ }^{33}$.

Ahora bien, en base a estos antecedentes proporcionados desde el ámbito de la Sociología, pero incorporando las adaptaciones necesarias que la perspectiva jurídica requiere; de esta forma, la propuesta teórica de justicia relacional realiza la identificación de las tres dimensiones -que, a su vez, encuentra explicación desde la idea de relación-. En este sentido, se mantiene -por los defensores de este enfoque- que la relación se entiende como vínculo recíproco, es decir, vinculación -o institucionalidad- $\mathrm{y}$ reciprocidad. Así pues, se instituye que estas dos dimensiones -de forma paralela a las mencionadas con anterioridad como semánticas estructural y referencial- se deben adaptar continua y recíprocamente en una dinámica de orientación a la justicia; siendo la justicia propiamente su efecto emergente, lo que, si efectivamente se produce, tiene lugar en la tercera dimensión, que denominamos socialidad -la relación, la red de relaciones, en generación continua-" 34 . Añadiéndose ${ }^{35}$ que se trata por tanto de una aproximación del

${ }^{29}$ Vid. MÁRQUEZ PRIETO, A. (2015): "La relación laboral como relación social (justicia relacional y socialidad común)"...op. cit., pág. 20.

30 Vid. MÁRQUEZ PRIETO, A. (2012): "Justicia relacional y fraternidad", en BAGGIO, A. M., COSSEDDU, A. y MÁRQUEZ PRIETO, A. (coord.). Fraternidad y justicia. Granada: Comares, págs. 5590.

${ }^{31}$ También denominada "simbólica", entendida como refero, según la cual la relación es una atribución de sentido, significado o intenciones Vid. DONATI, P. (2006): Repensar la sociedad...op. cit., págs. 92-93.

${ }^{32}$ Según la cual la relación se entiende como religo, consistente en generación de vínculos y dependencias mutuas. Ibídem., págs. 94-95.

${ }^{33}$ Esta semántica explica cómo se genera, de la interacción de los sujetos y agentes, algo distinto que lo que propiamente se puede llamar relación. Ibídem., págs. 95-96.

${ }^{34}$ Calificándose, al tiempo que se subraya por este autor, como un "planteamiento complejo", puesto que la justicia relacional exige ser explicada en base a la complejidad de la relación interpersonal. Vid. MÁRQUEZ PRIETO, A. (2015): "La relación laboral como relación social (justicia relacional y socialidad común)"...op. cit., pág. 21.

35 Importante contribución teórica, en el campo de la Filosofía Política, es el planteamiento integrador de Antonio María BAGGIO, quien aboga por una comprensión global, e interrelacionada, de los "tres principios revolucionarios modernos y de la socialidad correspondiente a los mismos -libertad, igualdad y fraternidad- y su aplicación al ámbito jurídico, en términos de utilidad”. Vid. BAGGIO, A. M. (2006): Il principio dimenticato. La fraternità nella rifessione politologica contemporánea, Roma (Italia): Città Nuova, passim. También puede consultuarse en BAGGIO, A. M. (2012): "La fraternidad como categoría política", en BAGGIO, A. M., COSSEDDU, A. y MÁRQUEZ PRIETO, A. (coord.). Fraternidad y justicia, Granada: Comares, págs. 3-18. Por otra parte, como ya hemos señalado con anterioridad, debemos insistir en la importante contribución que ha supuesto los estudios sobre la reciprocidad plural en las relaciones económicas, llevadas a cabo por BRUNI, Vid. BRUNI, L. (2006): Reciprocità...op. cit., págs. 55 y ss. 
denominado "giro relacional de la Sociología"36, liderado y propuesto por el sociólogo italiano.

Consecuentemente, una vez incorporadas las necesarias adaptaciones que la perspectiva jurídica requiere, se establece la necesidad de concretar las tres dimensiones mencionadas del enfoque de justicia relacional: institucionalidad, reciprocidad y socialidad; si bien, "(...) esta tarea se ha de realizar a través de la simple indagación de la relación jurídica que conduce, de forma natural, a constatar esas tres dimensiones" 37 . Precisamente, mediante la distinción de estas tres dimensiones, se explica la dinámica de la justicia relacional, abarcando en la misma, los contenidos y vacíos de justicia; además, mediante esta perspectiva tridimensional, se va a contribuir de forma útil a facilitar la aprehensión de conceptos y términos, como por ejemplo: "la relacionalidad jurídica", "la reciprocidad", "el principio relacional de fraternidad" o "la buena fe"; que por su aparente semejanza o proximidad, pueden inducir a error en determinadas ocasiones. Hecha esta salvedad, este proceso de interacción se explica partiendo de la relación jurídica, entendida como "vínculo recíproco -parte estructural: vinculación, institucionalidad; y parte dinámica: comportamiento recíproco en la necesaria adaptación continua entre esas dos dimensiones, con orientación común a la justicia, que puede producirse -o no- como efecto emergente de la interacción entre los sujetos, así como también de la interacción entre los dos mencionados aspectos o componentes de la relación" 38 .

No obstante, este enfoque tridimensional requiere de una aclaración más detallada, puesto que la dimensión de institucionalidad -parte estructural- y la dimensión de reciprocidad -parte dinámica- podrían ser considerados componentes de la relación, mientras que la dimensión de socialidad sería el resultado unitario de la acción bilateral de sus componentes. Sin embargo, este autor advierte que "(...) esta explicación podría ser parcial y equívoca. Porque, en primer lugar, no podemos experimentar de forma separada los componentes o aspectos de la relación, que se presenta siempre en su totalidad -aunque nos ayude separar dichos aspectos para una mejor comprensión-; y, en segundo lugar, la relación en sí misma, como tercera dimensión o elemento, no solo es un resultado, u output, sino que es continuamente también un input para las otras dos dimensiones, existiendo en realidad entre los tres aspectos una interacción simultánea"39.

Hecha esta aclaración, debemos añadir que las tres dimensiones de la relación institucionalidad, reciprocidad y socialidad- además de requerir una adaptación entre las mismas, deben orientarse hacia la justicia; teniendo presente, que de las tres dimensiones citadas, es la reciprocidad ${ }^{40}$ la que se interpone entre lo obligatorio y lo justo, abriéndose la oportunidad de alcanzar la justicia adoptando la estrategia de "ir más allá de la

\footnotetext{
${ }^{36}$ Vid. DONATI, P. (2006): Repensar la sociedad...op. cit., págs. 109 y ss.

37 Vid. MÁRQUEZ PRIETO, A. (2015): "La relación laboral como relación social (justicia relacional y socialidad común)"...op. cit., págs. 22-23.

${ }^{38}$ Véase dicho gráfico en Ibídem., pág. 22.

39 Debe advertirse, como añade este autor, que "la relación interpersonal, o, en general, el ambiente relacional, posee una vida propia y una inercia que influye continuamente en los sujetos, así como también en los aspectos estructural y dinámico de las relaciones entre los mismos". Ibídem., págs. 21-22.

${ }^{40}$ Sostiene y matiza este autor que "la necesaria apertura del Derecho a la reciprocidad requiere una comprensión de esta en clave jurídica", esto implica que el enfoque de justicia relacional no va a participar en la pugna que se ha mantenido tradicionalmente entre la norma y la justicia, ya que aspira a superar la fractura entre, lo jurídico-legal y lo jurídico-axiológico -entre lo obligatorio y lo justo-, es decir, apuntando a la justicia en la relación. Ibídem., págs. 24-25.
} 
norma"41-ya que no toma como referencia a la norma, sino a la relación-. En este sentido, se ha diseñado por su autor una original -y muy ilustrativa- representación gráfica de los cuatro puntos cardinales del ciclo de la justicia relacional, basándose en el compás musical de cuatro tiempos $(4 / 4)^{42}$. Siguiendo los cuatro tiempos que integran el compás (4/4), este autor identifica cada uno de ellos con las dimensiones que integran el ciclo de la justicia relacional. De esta forma, el número 0, situado en el tiempo de inicio, representa al modelo social de referencia, el número 1 representa la reciprocidad, el número 2 se corresponderá con la institucionalidad y el número 3 se identificará con la justicia. Así, los tiempos del compás correspondientes a los números 1, 2, 3, se corresponden con las dos primeras dimensiones de la relación jurídica, quedando dicha relación jurídica como conexión entre la institucionalidad y la reciprocidad, apuntándose que "la justicia relacional puede emerger de la relación, con el concurso conjunto de sus dos dimensiones integrantes" 43 . No obstante, la reciprocidad ocupará la posición central del esquema y por lo tanto se sitúa como el núcleo del ciclo de la justicia relacional.

Por otra parte, y atendiendo a los posibles movimientos cíclicos, podemos distinguir dos de ellos: un movimiento cíclico o dinámica vertical y otro horizontal. Respecto al primero de ellos, el ciclo vertical, consistente en "expresar mediante la actuación o conducta los valores propios del modelo social para, a la vez, generar, en la propia relación, un efecto de justicia que contribuya a recrear continuamente la socialidad (...) la reciprocidad, mediante otro ciclo horizontal -que es propiamente el juego jurídico-, asocia a la institucionalidad en el ciclo de la justicia, materializándose e institucionalizándose continuamente, a fin de procurar sostenibilidad a largo plazo e intentando que el efecto emergente de justicia se produzca mediante la acción simultánea de institucionalidad y reciprocidad" 44 .

Otra novedosa representación del ciclo de la justicia relacional es la que se realiza mediante la utilización de una ilustración gráfica que representa una noria de agua o molino hidráulico ${ }^{45}$. En dicho esquema, que tiene una estrecha relación con los descritos supra en este mismo epígrafe ${ }^{46}$, aunque este último lo hace de forma más dinámica -en la medida que se pretende representar en movimiento tanto las aspas del molino como el agua-. Su autor explica la identificación del ciclo de la justicia relacional en los siguientes términos: “(...) siguiendo el movimiento del agua, que, desde abajo -desde el caudal o corriente de agua, que está en la base de la noria, (punto 0), se eleva hasta el punto más alto (punto 3), -representado en el correspondiente gráfico al que nos hemos referido con anterioridad- mediante la flecha de giro exterior. La reciprocidad, como dimensión central, es la que impulsa el ciclo (paso 1), la que asume la iniciativa en el juego jurídico en el que necesita de la institucionalidad (paso 2) para que este juego entre las dos dimensiones -representado por la línea de giro interno del molino- tenga sostenibilidad

\footnotetext{
${ }^{41}$ Es decir, debemos insistir que ir más allá de la norma -del análisis normativo unidimensional, de la dimensión institucionalidad- supone dirigirse hacia la dimensión de la reciprocidad, que a su vez, conecta con la socialidad, como tercera dimensión, en la que se basa y a la que toma como modelo. Ibídem., pág. 25.

${ }^{42}$ Véase dicho gráfico en Ibídem., pág. 26.

${ }^{43}$ Ibídem., págs., 25-27.

44 Ibídem., pág. 26.

45 Vid. MÁRQUEZ PRIETO, A. (2017): “Justicia relacional: enfoque línea y método”, en MÁRQUEZ PRIETO, A. (Coord.) Justicia relacional y principio de fraternidad, Cizur Menor (Navarra): Aranzadi Thomson Reuters, pág. 178.

46 Pueden observarse dichos gráficos -representados en las págs. correspondientes que se indican- en MÁRQUEZ PRIETO, A. (2015): "La relación laboral como relación social (justicia relacional y socialidad común)"...op. cit., págs. 22 y 26.
} 
en el tiempo -y, haciendo girar internamente la noria, ésta haga girar el agua externamente-. Tanto el punto 0 como el punto 3 -momentos de inicio y cierre del ciclocorresponden a la dimensión de la socialidad (...) es la noria -institucionalidad, impulsada por la reciprocidad- la que remueve continuamente el agua, elevándola al punto superior (3), simbolizando el logro de la justicia en la relación -en la socialidad-. El punto 0 -que no es en sí mismo un paso, de ahí el número 0- simboliza el modelo social de justicia que la reciprocidad -primer paso del ciclo- toma como referencia" 47 .

\section{Vacíos de justicia.}

Por otra parte, y tal como se enfatiza desde el enfoque de justicia relacional, de la relación puede derivarse situaciones de ausencia de justicia y por lo tanto, han de conectarse estas situaciones de injusticia social con el vacío relacional. Será mediante el análisis de estos vacíos de justicia, que podrán estar presentes en cualquiera de las distintas fases de la dinámica de la justicia relacional como se podrá indagar sobre la causa que ha impedido que dicha justicia relacional se pudiera desarrollar. En este sentido, se puede constatar la existencia de vacíos de justicia ${ }^{48}$ en la mayoría de las relaciones laborales ${ }^{49}$. Del estudio de las posibles situaciones de ausencia de justicia, en el contexto de las relaciones laborales y basándose en el juego de la confianza, se llega a la conclusión de que "(...) no se establece la relación si no existe una verdadera motivación intrínseca" ${ }^{50}$. La principal consecuencia que podríamos extraer, y que este autor argumenta y explica detalladamente, es que la relación laboral no se consolidará como tal, le faltaría algo, afirmando en este sentido que la relación laboral no es "genuina" 51 . Teniendo en cuenta, que es indiferente, que la falta de motivación afecte a uno $\mathrm{u}$ otro sujeto de la relación laboral ${ }^{52}$ porque provocará el mismo efecto sobre la relación, es decir, que la relación transcurrirá de una forma mecánica, movida por lo estructural, lo obligacional, en definitiva guiada exclusivamente por la institucionalidad; y por lo tanto, desprovista de las otras dos dimensiones de carácter humano: la socialidad y la reciprocidad. Ante esta situación, y ante la necesidad de proponer soluciones que eviten el vacío de justicia, desde la perspectiva de la justicia relacional se sostiene que “(...) La única forma de salir de ese círculo vicioso, de esa relación desvirtuada, es iniciar una dinámica de reciprocidad fáctica, aun no perteneciendo al contenido de lo estrictamente contratado, que, yendo más allá de lo obligatorio, recupere, de forma interactiva, un trato recíproco verdaderamente satisfactorio desde el punto de vista humano, permitiendo pasar de la relación mercantil a la relación social"53.

\footnotetext{
47 Ibídem., págs. 177-178.

48 Para profundizar sobre los supuestos de vacíos de justicia en la relación laboral. Vid. MÁRQUEZ PRIETO, A. (2008): Repensar la justicia social... op. cit., págs. 181-187.

${ }^{49}$ Recuérdese que, de conformidad con el hilo conductor del presente trabajo, nuestro interés se centra en la indagación de los vacíos de justicia que puedan detectarse en las relaciones laborales en las que participen las personas trabajadoras que, por diversos motivos tales como la discapacidad, la edad, sus creencias, etc., están padeciendo situaciones de desigualdad y/o discriminación en el trabajo.

50 Vid. MÁRQUEZ PRIETO. A. (2015): "La relación laboral como relación social (justicia relacional y socialidad común)"...op. cit., págs.38- 42.

${ }^{51}$ Ibídem., pág.41.

${ }^{52}$ En este supuesto, se utiliza el ejemplo del juego de la confianza habla de "jugadores", como sujetos de dicho juego. En nuestro caso, al identificarlo con la realidad de la relación laboral, hablamos de sujetos de dicha relación laboral. Para profundizar sobre el tema véase MÁRQUEZ PRIETO. A. (2014): "La justicia relacional como círculo virtuoso"...op. cit., págs. 126- 130.

53 Vid. MÁRQUEZ PRIETO. A. (2015): "La relación laboral como relación social (justicia relacional y socialidad común)”...op. cit., págs. 41- 42.
} 
Al hilo de lo expuesto, y con el fin de poder ofrecer una aplicación práctica del tratamiento teórico-conceptual desarrollado supra, se aportan un elenco de supuestos concretos de vacíos de justicia en la relación laboral -sin carácter exhaustivo- haciendo referencia a diversas situaciones que son ejemplos de ausencia de justicia y que van a suponer, en todos los casos, auténticas barreras que impedirán, a buen seguro, el correcto funcionamiento del modelo relacional. Advirtiéndose, que con carácter previo al abordaje del correspondiente análisis, se debe observar la diligencia debida para evitar la posible confusión -por las similitudes que puedan apreciarse a priori entre ambos modelos- con el modelo europeo de relaciones laborales ${ }^{54}$. Así, según este autor, existirían vacíos de justica en los supuestos siguientes:

El vacío de justicia más habitual, que se detecta en el ámbito de las relaciones laborales, es el relativo a la carencia de normas reguladoras, que el profesor ha denominado: "ausencia de las normas e instituciones indispensables para que las relaciones laborales puedan funcionar según una estructura de red". Desde el enfoque relacional, y en la medida que se detecte esta ausencia de normas o instituciones, indispensables para que se produzca el adecuado funcionamiento y desarrollo de la relación laboral, se estará afectando directamente a la dimensión denominada institucionalidad, es decir, aquella que está integrada por lo estructural, lo obligacional. Además, no debemos olvidar el importante papel que desempeña en este caso, según se ha explicado con anterioridad, la cultura jurídico-social de cada colectividad que subyace $\mathrm{y}$, que también, forma parte de los contenidos propios de la dimensión conocida como socialidad. En este sentido, se ha señalado con cierto énfasis -por la importante repercusión que va a tener en este supuesto que analizamos- "(...) la enorme relevancia de los contenidos de justicia social, presentes en las normas estatales que aseguran unos niveles mínimos, y que funcionan como base, ámbito o contexto de la red, dentro del cual también se incluye la cultura jurídico social propia de cada colectividad" 55 . Ante las carencias expresadas, nos preguntamos ¿cómo actuar desde el enfoque relacional para suplir estos vacíos de justicia? Evidentemente, la respuesta no es sencilla, pues como se apunta desde el enfoque relacional “(...) sobre la red se puede construir tejiendo relaciones formales e informales (...) siendo preciso para que funcione adecuadamente que las relaciones sean lo suficientemente densas y plurales, contando para ellos con instituciones de implicación y participación de los trabajadores en la empresa y con los diversos instrumentos de la negociación colectiva" ${ }^{56}$. Obsérvese que ante este vacío causado por la ausencia de institucionalidad, no bastaría con suplir simplemente la norma, haría falta añadirle el plus de la relacionalidad, como se ha puesto de manifiesto por Tiziano TREU "actualmente se hace necesaria una relacionalidad adaptada al nuevo contexto internacional" 57 ; es decir, esa norma tiene que mirar hacia las conductas y los

\footnotetext{
${ }^{54}$ Este autor añade una importante aclaración sobre el modelo relacional, afirmando que "a pesar de que el modelo europeo de relaciones laborales podría considerarse muy próximo, en la medida en que constituye una realización normativa muy valiosa desde la vertiente del eje de la relacionalidad, nuestra referencia no es a dicho modelo, sino al que correspondería en realidad a la justicia relacional, que exige la puesta en juego de una dinámica bilateral por parte, tanto del eje de relacionalidad como de reciprocidad (...)" Vid. MÁRQUEZ PRIETO, A. (2008): Repensar la justicia social... op. cit., pág. 181.

${ }^{55}$ Ibídem., pág. 185.

56 Ibídem., págs. 182-184.

57 Tiziano TREU, profesor italiano y ex ministro de Trabajo y Seguridad Social, destaca el hecho de que "la globalización altera todos los términos de referencia de las relaciones industriales. Las instituciones públicas de regulación no consiguen encontrar vehículos consistentes a nivel supranacional -ni siquiera en la Europa comunitaria-. También los agentes sociales están atrasados, a nivel internacional, respecto a las instituciones económicas y financieras". Vid. TREU, T. (1999): "Sviluppare la competitività e la giustizia
} 
comportamientos de los sujetos intervinientes en la relación laboral, refiriéndosenos a la reciprocidad, y además, no puede ignorar -como hemos indicado con anterioridad- la socialidad, que integrada por la cultura jurídico-social va a impregnar a las otras dos dimensiones. En este sentido, se sostiene que “(...) la vía más directa para la convergencia social internacional es la proyección a escala supranacional de los institutos tradicionales de las relaciones industriales: contratación colectiva, forma de participación de los trabajadores y organizaciones sindicales" ${ }^{\circ 8}$; en definitiva, hacen falta las necesarias instituciones indispensables para que las relaciones laborales puedan funcionar según una estructura de red.

Otro vacío de justicia, que lamentablemente se detecta con una alta frecuencia en las relaciones laborales, es aquel que está relacionado con la falta de paridad y simetría en la propia relación, lo que llevará implícito una carencia de participación. La perspectiva relacional, propone como solución que “(...) de forma inmediata y previa al funcionamiento de la dinámica de reciprocidad, el eje de relacionalidad arbitre fórmulas oportunas para establecer o restablecer la paridad"59. El profesor ha denominado a esta dinámica con el término "expediente de inclusión" 60 , que consiste en promover la inclusión social de los sujetos no incluidos en la relación de interdependencia en condiciones de simetría social para que lleguen a ser "capaces de reciprocidad" 61. También, en este sentido, el profesor dice que "(...) el Derecho del Trabajo funciona o debe funcionar como permanente 'expediente de inclusión' heterónomo, aunque son preferibles -y más adecuados a la idea de justicia relacional- los 'expedientes de inclusión' consistentes en soluciones autónomas" ${ }^{2}$. Un buen ejemplo en el que se pretende evitar la falta de paridad y la carencia de participación, se puede apreciar en la Directiva 2001/86/CE ${ }^{63}$ del Consejo, de 8 de octubre de 2001, por la que se completa el Estatuto de la Sociedad Anónima Europea en lo que respecta a la implicación de los trabajadores, establece en su considerando núm. 2 que "(...) un cuadro jurídico uniforme en cuyo ámbito las sociedades de los diversos Estados miembros sean capaces de programar y ejecutar la reorganización de sus actividades a nivel comunitario"; de igual forma de su considerando núm. 18, se desprende que “ (...) la reorganización de sus actividades deben realizarse en el modo más rápido y con menos gravámenes, y no tienen que constituir la ocasión para anular o reducir derechos colectivos ya 'adquiridos' por los trabajadores en las empresas interesadas en constituir una Sociedad Anónima Europea"

También, el supuesto de ausencia de la nota de pluralismo o de la idea pluralista de empresa puede ser la causa de un significativo vacío de justica en la relación laboral. El profesor ha manifestado que en este caso, “(...) las relaciones industriales son una

sociales: le relazioni tra istituzioni e parti sociali", en VV. AA. Studi sul lavoro. Scritti in onore de Gino Giugni (Tomo II), Bari (Italia): Cacucci, pág. 1324.

${ }^{58}$ Ibídem, pág. 1327.

59 Vid. MÁRQUEZ PRIETO, A. (2008): Repensar la justicia social... op. cit., págs. 181-182.

${ }^{60}$ Ibídem., pág. 183.

${ }^{61}$ Entendiéndose por "expediente de inclusión” aquel mecanismo relacional -suscitado necesariamente por la dimensión institucional del sistema jurídico- que exige integrar en la dinámica jurídica las situaciones de asimetría; es decir, “ (...) emancipar -autónoma o heterónomamente- lo sometido, lo subordinado, sobre todo en sus grados más acusados, pero también en otros niveles de menor gravedad, tratando así de conciliar la dependencia con la interdependencia". Vid. MÁRQUEZ PRIETO, A. (2017): "Justicia relacional: enfoque línea y método”... op. cit., pág. 172.

${ }^{62}$ Vid. MÁRQUEZ PRIETO, A. (2008): Repensar la justicia social... op. cit., pág. 182.

${ }^{63}$ Vid. DOCE núm. 294, de 10 de noviembre de 2001, págs. 22-32.Ref. DOUE-L-2001-82442.

${ }^{64}$ Se puede acceder a elaborado y completo comentario sobre esta Directiva en ARRIGO, G. (2004): "La implicación de los trabajadores en la sociedad europea", Revista del Ministerio de Trabajo y Asuntos Sociales. Derecho social Internacional y Comunitario, núm. 52, págs.13-29. 
expresión lógica pluralista de representación de los intereses -superando la concepción monista o unitaria de la empresa-, dentro de la cual constituyen un elemento esencial la dimensión negocial y la contratación colectiva" ${ }^{65}$. Así, retomando el examen de la citada Directiva 2001/86/CE ${ }^{66}$ del Consejo, de 8 de octubre de 2001, por la que se completa el Estatuto de la Sociedad Anónima Europea en lo que respecta a la implicación de los trabajadores, se puede apreciar como la consolidación de los derechos de la información, consulta y participación en los procesos de modificación y reorganización de la empresa en el ámbito transnacional -en referencia a la sociedad europea y a la cooperativa europease produce como parte integrante esencial del modelo social europeo ${ }^{67}$. También, y en relación directa con este tema, conviene recordar el análisis que hacía supra el profesor BRUNI ${ }^{68}$ en relación a la Teoría de juegos, sobre la dinámica de la reciprocidad que, como efecto red, se producía el mismo en el contexto cuatridimensional, es decir "(...) en un ámbito de interacciones lo suficientemente denso y heterogéneo"69.

La falta o carencia de justicia en la relación, también se puede apreciar en aquellos casos en los que se va a generar un fraude entre la parte empresarial y la parte trabajadora, promovidos esencialmente por una falta de sinceridad o genuinidad en el compromiso de participación que se solicita desde la empresa a los trabajadores; y que, se distancia lógicamente de aquella que se desprende de los cánones de calidad previstos para la participación de los trabajadores en la empresa. Al hilo de lo expuesto, y en relación directa con la importancia que supone para la realidad empresarial actual, contar en su plantilla con trabajadores que poseen una alta y especializada cualificación, se impone cada vez más la implantación de técnicas orientadas a la consecución de la "fidelización" de los empleados. CATALANO y MALANDRINI, proponen dos técnicas para aumentar la fidelidad del trabajador: "a) de tipo económico, que tratan de satisfacer exclusivamente exigencias retributivas y b) de satisfacción de exigencias personales de los trabajadores, como son, por ejemplo, la flexibilidad en la determinación del tiempo de trabajo. Debiendo incluso tenerse en cuenta que la mezcla de ambas técnicas, puede para algunos, resultar contraproducente -poco rentable- desde el punto de vista empresarial, puesto que al trabajador que ya se encuentra satisfecho por la adaptación de su horario de trabajo no le supone un incentivo adicional significativo contar con una retribución económica complementaria; y, al contrario, quien no se encuentra satisfecho a nivel personal a pesar de la adopción de técnicas específicamente ideadas, tampoco se sentirá compensado por la existencia de retribuciones complementarias" 70 .

Un vacío de justicia adicional se encuentra en aquellas situaciones en las que puede existir reciprocidad en una cooperación sin justicia, calificada como "reciprocidad de la corrupción”. En este sentido, argumenta el profesor que "(...) el consenso por sí mismo, no basta, si no se trata de una cooperación en la justicia. Convirtiéndose el vacío de justicia en una amenaza radial al desarrollo del modelo relacional, que exige (...) una vinculación recíproca entre relacionalidad y justicia"71. El profesor MONTEIRO FERNANDES, refiriéndose a las posibles causas que motivan estas prácticas en la

\footnotetext{
${ }^{65}$ Vid. MÁRQUEZ PRIETO, A (2008): Repensar la justicia social... op. cit., pág. 183.

${ }^{66} \mathrm{Vid}$. DOCE núm. 294, de 10 de noviembre de 2001, págs. 22-32.Ref. DOUE-L-2001-82442.

${ }^{67}$ Vid. ARRIGO, G. (2004): "La implicación de los trabajadores en la sociedad europea"...op.cit., passim.

${ }^{68}$ Vid. BRUNI, L. (2006): Reciprocità. Dinamiche di cooperazione, economia e società civile...op. cit., passim.

69 Vid. MÁRQUEZ PRIETO, A. (2008): Repensar la justicia social... op. cit., pág. 183.

${ }^{70} \mathrm{Vid}$. CATALANO, A. y MALANDRINI, S. (2006): "Costo del lavoro e nuovi modelli organizzativi”, en MALANDRINI, S. y RUSSO, A.: Lo sviluppo del 'capitale umano' tra innovazione organizzativa e tecniche di fidelizzazione, Milano (Italia): Giuffré Editore, pág. 73.

${ }^{71}$ Vid. MÁRQUEZ PRIETO, A. (2008): Repensar la justicia social... op. cit., pág. 185.
} 
realidad socio-laboral portuguesa, dice que "(...) esta cultura -o contracultura existe en Portugal y quizá en la mayor parte de los países de la Europa meridional”. Se explica probablemente por un amplio conjunto de factores, del que forman parte la debilidad de las tradiciones industriales y sindicales y la lenta maduración de una civilización democrática. Dentro de la misma lógica, entre las causas de inefectividad del Derecho del Trabajo se señala la debilidad del llamado "aparato de tutela": inspección, magistratura del trabajo, representaciones sindicales en el lugar de trabajo"72. Este autor también hace referencia a supuestos de consenso ilegítimo, que se producen en Portugal y que, según su criterio, podrían ser extrapolables a otros países de la franja meridional europea, consistentes en un incumplimiento generalizado del ordenamiento jurídico laboral. Así por ejemplo, hace referencia a la práctica normal y habitual sobre el incumplimiento de las normas reguladoras del contrato temporal de trabajo; siendo muy reducidos y extraños los procesos judiciales sobre esta materia, debido a los acuerdos ilegítimos alcanzados entre el empresario y el trabajador. Otro supuesto muy generalizado, es el relativo a la simulación del trabajo autónomo "falsos autónomos", en relaciones que son claramente de tipo laboral, también basado en la correspondiente connivencia entre el empresario y trabajador en la que se pacta la percepción de una retribución económica más elevada ${ }^{73}$.

A la hora de abordar la metodología ${ }^{74}$ sobre la aplicación práctica del enfoque de justicia relacional, se puede apreciar como denominador común la insistencia en que "la idea de justicia relacional consiste en algo a la vez más simple y completo que el hecho de intentar que no se produzcan los vacíos anteriores"75. Recordemos en este sentido que la falta de justicia, se produce en situaciones en que no existe una verdadera justicia relacional, por ello los vacíos de justicia son desequilibrios que se manifiestan por un déficit de adaptación de la relacionalidad a la reciprocidad o al contrario, por un déficit de la reciprocidad con respecto a la relacionalidad ${ }^{76}$; sin embargo, como Gunter TEUBNER ha puesto de manifiesto en referencia a la idea de la constitucionalización civil o social, en las relaciones de intercambio entre lo empresarial y lo personal constituye un entrelazamiento en el que el eje de la reciprocidad cobra un protagonismo destacado que hace que esta dimensión asuma la iniciativa ${ }^{77}$.

Por otra parte, recordando y, a su vez, subrayando que el enfoque de justicia relacional tiene un carácter eminentemente pragmático ${ }^{78}$, conviene hacer una referencia en este

\footnotetext{
72 Vid. MONTEIRO FERNANDES, A (2006): "L'effettività nel Dirirtto del lavoro: il caso portoghese", Revista Italiana di Diritto del lavoro, núm. 1: pág. 17.

${ }^{73}$ Ibidem., págs. 7-19.

${ }^{74}$ Vid. MÁRQUEZ PRIETO, A. (2017): “Justicia relacional: enfoque línea y método”...op. cit., págs. 198215.

${ }^{75}$ Vid. MÁRQUEZ PRIETO, A. (2008): Repensar la justicia social... op. cit., pág. 185.

76 Precisamente con el fin de colmar dichos vacíos, podremos encontrar muy buenos ejemplos -de aplicaciones prácticas- en aquellas Directivas comunitarias dedicadas a fomentar el espíritu de cooperación en la empresa. Concretamente la Directiva 2001/86/CE del Consejo, de 8 de octubre de 2001, por la que se completa el Estatuto de la Sociedad Anónima Europea en lo que respecta a la implicación de los trabajadores (arts. 4 y 9); Directiva 2002/14/CE del Parlamento Europeo y del Consejo, de 11 de marzo de 2002, por la que se establece un marco general relativo a la información y a la consulta de los trabajadores en la Comunidad Europea - Declaración conjunta del Parlamento Europeo, el Consejo y la Comisión relativa a la representación de los trabajadores (art. 1.3) y la Directiva Directiva 2003/72/CE del Consejo, de 22 de julio de 2003, por la que se completa el Estatuto de la sociedad cooperativa europea en lo que respecta a la implicación de los trabajadores (arts. 4 y 11). Para profundizar sobre este tema, puede consultarse en MÁRQUEZ PRIETO, Antonio. Repensar la justicia social... op. cit., págs. 14, 186-187.

77 Vid. TEUBNER, Gunther. La cultura del diritto nell'epoca della globalizzazione. L'emergere delle constituzioni civilli...op. cit., passim.

${ }^{78}$ Vid. MÁRQUEZ PRIETO, A. (2017): Justicia relacional y principio de fraternidad...op. cit., pág. 199.
} 
sentido a Friedrich Carl von SAVIGNY, pues para este distinguido jurista era en la práctica, y no en un orden lógico, donde puede encontrarse un verdadero fundamento jurídico, que se concretaba precisamente -según sus propias expresiones- en la conexión entre "vida social, relaciones jurídicas e institutos" -que fácilmente se podrían asimilar a la reciprocidad, socialidad e institucionalidad"79-. En este sentido, utilizaremos el método que nos aporta este enfoque experimental ${ }^{80}$ para analizar los contenidos o vacíos de justicia que se producen en el ámbito de de aquellas situaciones de desigualdad y/o discriminación, de determinados colectivos de personas trabajadoras que, por diversas razones -discapacidad, edad, sexo, etc.-, sufren con respecto al resto de los trabajadores.

Sobre la utilización de este método, se han propuesto tres postulados metodológicos generales que reproducimos a continuación ${ }^{81}$ :

En primer lugar, que se han de distinguir las tres dimensiones de la relación jurídica, pero sin perder de vista que cada una de las dimensiones tiene sentido en relación a las otras dos, procurando obtener una visión de conjunto.

En segundo lugar, que el análisis de cada una de las dimensiones ha de ser necesariamente crítico, indagando la posible existencia de vacíos de justicia.

En tercer lugar, que aunque la visión de la relación jurídica se intente contextualizar en la socialidad de relaciones, y aunque el cuestionamiento sobre la justicia esté centrado en el comportamiento, en la medida en que se pretende un análisis jurídico -aun en un contexto interdisciplinar, que resulta enriquecedor para las dimensiones de socialidad y reciprocidad principalmente-, ha de ser la dimensión de la institucionalidad la que marque la argumentación, sin agotarla, quedando abierta a diversos matices posibles ${ }^{82}$.

\section{Expediente de inclusión.}

Ahora bien, en atención a las ideas propuestas y ante la problemática que se suscita sobre las situaciones de desigualdad y/o discriminación, de determinados colectivos de personas trabajadoras que por diversas razones sufren con respecto al resto de los trabajadores. En tal sentido, la OIT entiende por discriminación en el empleo y la ocupación "cualquier distinción, exclusión o preferencia basada en motivos de raza, color, sexo, religión, opinión política, ascendencia nacional u origen social que tenga por efecto anular o alterar la igualdad de oportunidades o de trato en el empleo y la

\footnotetext{
79 Vid. SAVIGNY, F. C. (2005): Tratado de la posesión. MONEREO PÉREZ, J. L. (dir.), Granada: Comares, passim.

${ }^{80}$ Efectivamente se trata de un método en proceso de maduración, desde el equipo investigador y a través de la dirección del mismo se asume como "un intento, al menos, de plantear cuestiones, más allá de las respuestas que se proponen, y que podrían, lógicamente, ser compartidas por unos y rechazadas por otros". Vid. MÁRQUEZ PRIETO, A. (2008): Repensar la justicia social... op. cit., pág. 14. En la actualidad, y con ocasión de la publicación de su obra colectiva Justicia relacional y principio de fraternidad -a la que nos hemos referido con anterioridad y aportamos como referencia bibliográfica- se sigue insistiendo en el hecho de que se trata de un método en proceso de maduración en el ámbito del equipo de investigación que constituye la Red internacional de estudios interdisciplinares sobre justicia relacional en el contexto del principio jurídico-político de fraternidad -RIF-. Especial consideración requieren los estudios de carácter práctico -llevados a cabo por investigadores de la Red mencionada- que mediante la aplicación de la metodología de análisis, alimentada desde el enfoque de justicia relacional, se han llevado a cabo y de cuya maduración colectiva son también buenos ejemplos los seis capítulos finales de la obra. Vid. MÁRQUEZ PRIETO, A. (2017): Justicia relacional y principio de fraternidad...op. cit., págs. 219-in fine.

${ }^{81}$ Ibídem., págs. 198-215.

${ }^{82}$ Ibidem., pág. 199.
} 
ocupación" 83 . Se trata de realidades en la que una persona trabajadora se ve perjudicada profesional, salarial o moralmente respecto al resto de trabajadores por motivos que no están directamente relacionados con su actividad laboral. Es decir, la discriminación en el trabajo se produce cuando un trabajador presenta alguna diferencia con respecto al resto de la plantilla de la empresa o centro de trabajo, bien de tipo físico -como sucede con el origen étnico, el género, discapacidad o la incidencia de alguna enfermedad-, o de tipo cultural -como la nacionalidad o creencia religiosa-. El efecto que provoca en dichos trabajadores dará como resultado: horarios abusivos, salarios más bajos, acoso o ataques personales, pérdida de las opciones de promoción profesional, etc.

Sin embargo, dichas prácticas pueden dar lugar a situaciones de discriminación directa e indirecta. La primera de ellas se va a originar cuando se establezca una distinción, exclusión o preferencia explícita por uno o varios motivos de los expresados con anterioridad. Algunos ejemplos serían los siguientes: el establecimiento de una condición para el ascenso o promoción del mismo basada en razones de género exclusivamente para hombres-; descartar la candidatura de una persona en un proceso de selección por la raza de que proviene; no tomar en cuenta la opinión de una persona por ser mujer; rescindir el contrato de trabajo de una persona por contraer una enfermedad; el acoso sexual de un jefe a su secretaria; incumplimiento de los derechos laborales en el caso de embarazo, puerperio o lactancia natural, etc.

Por su parte, la discriminación indirecta contempla aquellas medidas, situaciones o prácticas aparentemente neutrales pero que en realidad tienen un efecto negativo y perjudicial en las personas trabajadores pertenecientes a un colectivo determinado -por ejemplo trabajadores con una determinada orientación sexual o de mayor edad-. Esta categoría de discriminación, debido a su naturaleza más oculta, puede pasar fácilmente desapercibida $\mathrm{y}$, por tanto, es la más difícil de detectar y atajar. Una práctica de discriminación indirecta por parte del empresario sería por ejemplo la organización de cursos de perfeccionamiento profesional a horas tardías, impidiendo a los trabajadores con responsabilidades familiares -de forma indirecta y sutil- la posibilidad de poder acudir a los mismos. Provocando de forma indirecta, y como resultado de esta práctica, que estos trabajadores con menos formación estén en una posición de desventaja respecto a la asignación posterior de tareas y posibilidades de promoción.

Consecuentemente, ambos tipos de discriminación -directa e indirecta- inciden de forma negativa en las relaciones laborales presentándose como un potente factor desestabilizador que tiene a su vez un hondo impacto en la sociedad. Por tanto, para poder lograr la eliminación en el empleo y la ocupación, no bastará con erradicar simplemente estas prácticas discriminatorias; además, será indispensable promover la igualdad de oportunidades y de trato en las relaciones laborales ${ }^{84}$, de tal forma que permita a todas las personas trabajadoras desarrollar plenamente sus capacidades y cualificaciones de conformidad con sus preferencias para que puedan gozar de igualdad respecto de las condiciones de trabajo y acceso al empleo.

Ante la complejidad de la casuística presentada, nos preguntamos: ¿cómo deberíamos enfrentarnos a esta realidad desde el enfoque relacional? Sin duda, la respuesta al

\footnotetext{
${ }^{83}$ Vid. art. 1, a) del Convenio de la OIT sobre la discriminación (empleo y ocupación), 1958 (núm. 111). Apuntándose en dicho Convenio que no serán consideradas como discriminación: "las distinciones, exclusiones o preferencias basadas en las calificaciones exigidas para un empleo determinado".

${ }^{84}$ Es decir, propiciándose dicha igualdad de oportunidades y de trato en el trabajo en todas y cada una de las fases que conforman el mismo, incluidas la promoción profesional, acceso a la jubilación, remuneración, complementos salariales, formación profesional, desarrollo de las competencias profesionales, etc.
} 
problema planteado no es sencilla; no obstante, podríamos abordar el tratamiento de dichas desigualdades $\mathrm{y} / \mathrm{o}$ discriminaciones, desde la perspectiva relacional ${ }^{85}$, reflexionando sobre la idea de que una gran cantidad de aspectos y ámbitos del Derecho del Trabajo, de la Seguridad Social, de Prevención de Riesgos Laborales, etc., en general están relacionados con la protección jurídica de estos colectivos ${ }^{86}$. Sin embargo, desde el enfoque de justicia relacional no es compatible la realización de un tratamiento jurídico protector frente a la discriminación o desigualdad de estas personas trabajadoras de forma fragmentada o diseccionada ${ }^{87}$. Esta técnica llevaría implícita una doble consideración: la de la regulación jurídica de los trabajadores en general y la de aquellos que tienen especiales necesidades de protección. A contrario sensu, y desde el enfoque de justicia relacional, y como propuesta de lege ferenda, se sostiene que es mucho más adecuada la visión integral de la relación laboral como relación social, pretendiendo el Derecho del Trabajo $^{88}$ la inclusión del trabajador en un conjunto de relaciones sociales y en términos de justicia. Siendo esa misma finalidad, unitaria y esencial, la que ha de jugar a favor de las personas trabajadoras en situaciones de discriminación y/o desigualdad ${ }^{89}$.

Adviértase que, desde el punto de vista relacional -como hemos analizado con anterioridad y que defendemos como enfoque viable-, las situaciones de discriminación y/o desigualdad en las que se encuentran determinados colectivos de personas trabajadoras son abordadas como necesidad o dependencia que se inscribe en la relación interpersonal, por lo que es necesario promover la inclusión social, de los sujetos no incluidos en la relación de interdependencia, en condiciones de simetría social ${ }^{90}$-al que

\footnotetext{
${ }^{85}$ Precisamente, y como muestra de la preocupación actual sobre esta problemática por parte de los juristaslaboralistas, dicho tema sería tratado en el XIII Congreso jurídico de la abogacía organizado por el Ilustre Colegio de Abogados de Málaga, celebrado durante los días 5 y 6 de octubre de 2017 en Marbella (Málaga). A propuesta de la Sección de Diversidad Funcional, y enmarcado en la ponencia titulada: "La nueva Ley andaluza de Derechos y Atención a las personas con discapacidad", se disertó sobre la esencia y características fundamentales del modelo relacional, así como, las estrategias y metodología empleada para abordar el problema de las personas trabajadoras con discapacidad desde el punto de vista relacional. Vid. MÁRQUEZ PRIETO, A. (2017): "La nueva Ley andaluza de Derechos y Atención a las personas con discapacidad", en XIII Congreso jurídico de la abogacía ICA Málaga: celebrado el 5 y 6 de octubre de 2017. Marbella (Málaga): Ilustre Colegio de Abogados de Málaga.

${ }^{86}$ Aunque la casuística es muy extensa, a modo de aproximación, destacamos y seleccionamos los siguientes supuestos: las prestaciones sociales por discapacidad o dependencia, el establecimiento de centros especiales de empleo -CEE-, la proscripción de todo tipo de discriminación por razón de la discapacidad, el acceso al empleo de personas con discapacidad, el fomento de la contratación de las personas con discapacidad a través de subvenciones o bonificaciones en las cotizaciones a la Seguridad Social, o a través el establecimiento de cuotas de contratación en empresas públicas o privadas para personas con discapacidad, etc.

${ }^{87}$ Reflexionando sobre esta idea, significa que el fenómeno de la discapacidad se aborda con una atención parcial, acentuada o especial, dentro del ámbito del Derecho del Trabajo, de la Seguridad Social, de la Prevención de Riesgos Laborales, etc. Es decir, considerar estas disciplinas como un conjunto de normas, incluyendo, dentro de ese conjunto, a algunas que se refieren a la discapacidad directa o indirectamente.

${ }^{88}$ Entendemos que se incluyen además, todas las disciplinas afines enumeradas con anterioridad por el profesor y que hacen referencia a las materias de Prevención de Riesgos Laborales, Empleo, Seguridad Social, etc.

${ }^{89}$ Vid. MÁRQUEZ PRIETO, A. (2017): “La nueva Ley andaluza de Derechos y Atención a las personas con discapacidad"...op.cit., passim.

${ }^{90}$ Desde la propia esencia del enfoque de justicia relacional se desprende la idea de que únicamente es posible el adecuado funcionamiento de las relaciones sociales interdependientes y recíprocas si se llevan a cabo partiendo previamente de una simetría social y afirmando en este sentido que cualquier solución jurídica inspirada por la idea de justicia relacional ha de pretender, ante todo, "horizontalizar" y nivelar las posiciones de asimetría social producidas por tantas situaciones de necesidad, de dependencia, de capacidades cercenadas o no desarrolladas. Sobre este asunto, y con especial consideración sobre su tratamiento actual, se destaca el análisis crítico que realiza Martha NUSSBAUM sobre la idea de
} 
se ha hecho referencia supra, aunque de forma muy breve, a la hora de examinar los distintos supuestos de vacíos de justicia- y que desde el enfoque de justicia relacional se conoce con el término de "expediente de inclusión", entendido como "el mecanismo relacional -que ha de ser suscitado necesariamente por la dimensión institucional del sistema jurídico- que exige integrar en la dinámica jurídica las situaciones de asimetría" $"$.

Otra concepción del "expediente de inclusión", contextualizada y adaptada a la realidad del entorno empresarial, como estrategia de intervención propuesta desde este enfoque relacional, sería aquel consistente en la realización, como estrategia previa, de un mínimo mecanismo necesario para promover una simetría social de partida, que facilite, conforme a la propuesta de justicia relacional, el libre juego de la interdependencia recíproca, desde una pluralidad de actitudes personales. Pero, sobre todo, teniendo en cuenta que "la relación laboral es de tracto sucesivo, con efectos deseablemente estables y duraderos, y considerando que la organización empresarial de la gestión del trabajo es fuente constante de dependencia, en la medida en que ambas partes no se conduzcan voluntariamente con arreglo a una exquisita intención de justicia, queda el Derecho del trabajo ${ }^{92}$, con sus normas estatales o colectivamente pactadas, constituido en permanente expediente de inclusión" 93 .

Así por ejemplo, si nos centramos en el tratamiento concreto de las situaciones de discriminación que padecen las personas trabajadoras con discapacidad en el contexto de las relaciones laborales, el debate actual se centra sobre la forma de concebir el fenómeno de la discapacidad ${ }^{94}$, que por una parte enfrenta a un sector doctrinal que sostiene la presencia de un único modelo, el modelo social, frente a otro sector que defiende la existencia -en su lugar- del paradigma de la autonomía personal -integrado a su vez por el modelo social y el de la diversidad funcional-. Nuestro posicionamiento se sitúa en la línea dogmática que representa el paradigma de la autonomía personal, pues dicho paradigma es esencialmente relacional ${ }^{95}$, presentando aspectos en común con el enfoque de la justicia relacional. Sin embargo, este sometimiento o subordinación, que se aprecia

cooperación social de John RAWLS, afirmando que dicha cooperación social "está basada en la idea de la reciprocidad entre individuos aproximadamente iguales, y no deja explícitamente espacio alguno para las relaciones de dependencia extrema". Vid. NUSSBAUM, M. (2002): Giustizia sociale e dignità umana. Da individui a persone, Bolonia (Italia): Il Mulino, pág. 111.

${ }^{91}$ Vid. MÁRQUEZ PRIETO, A. (2017): “Justicia relacional: enfoque línea y método"...op. cit., pág. 172.

92 Tal como se ha expresado con anterioridad, debe entenderse que esta referencia al Derecho del trabajo también incluye otras disciplinas afines como Prevención de Riesgos Laborales, Empleo, Seguridad Social, etc.

${ }^{93}$ Vid. MÁRQUEZ PRIETO, A. (2017): "Justicia relacional: enfoque línea y método"...op. cit., pág. 173.

${ }^{94}$ Destacando la mejora y el progreso -señalado por parte de la doctrina- que se produce con el paso de los paradigmas de etapas históricas anteriores al actual de la autonomía de la voluntad. Vid. CAMPOY CERVERA, I. (2007): Los derechos de las personas con discapacidad. Perspectivas sociales, políticas, jurídicas y filosóficas, Madrid: Dykinson, pág. 10. También, y en este mismo sentido se puede ver en VICTORIA MALDONADO, J. A. (2013): "El modelo social de la discapacidad: una cuestión de derechos humanos", Boletín Mexicano de Derecho Comparado, núm. 138, págs. 1094-1095. Además, conviene tener muy presente que el modelo de la diversidad funcional se diferenciaba del modelo social por poseer una perspectiva de análisis tridimensional, abarcando el plano jurídico, social y bioético; por ende, los principios fundamentales sobre los que se sustentan son: la diversidad, la igualdad y la dignidad -tanto en su dimensión intrínseca como la extrínseca- y la clave para delimitar la pertenencia a este grupo no está en la diversidad funcional sino en la discriminación. Vid. VELARDE LIZAMA, V. (2012): "Los modelos de la discapacidad: un recorrido histórico", Revista Empresa y Humanismo, vol. XV, núm. 1, pág. 132.

95 Adviértase que analizar e indagar sobre el carácter relacional -o no relacional- del paradigma de la autonomía personal, lleva implícito extender el reconocimiento de este carácter al modelo social, por quedar este integrado en el citado paradigma. 
con una mayor intensidad en aquellos supuestos en los que uno de los sujetos intervinientes en la relación laboral es una persona trabajadora con discapacidad o en cualquier otra situación de desigualdad y/o discriminación con respecto al resto de los trabajadores ${ }^{96}$, requiere una actuación que libere dicho sometimiento, bien sea de forma autónoma o de forma heterónoma, buscando la necesaria armonización de la dependencia con la interdependencia. Es decir, que mediante la aplicación metodológica que el enfoque de la justicia relacional propone, y ante una necesidad que podemos detectar desde el ámbito de reciprocidad -en base a la interdependencia-, se deberá actuar mediante la puesta en práctica del "expediente de inclusión" 97 , como programa previo imprescindible, de tal forma que este mecanismo relacional corrija la asimetría social, y así, se pueda restablecer y facilitar el buen funcionamiento de la interdependencia recíproca. Ahora bien, ¿cómo podríamos efectivamente materializar esta actuación? Sin duda, la respuesta nos vendría dada desde la estrategia metodológica que nos proporciona la perspectiva relacional, deduciendo de la misma que será la dimensión de la institucionalidad la que ha de asumir el desafío de ofrecer un plano jurídico de paridad, de simetría, corrigiendo, ante todo, los desequilibrios existentes ${ }^{98}$.

\section{Conclusiones.}

Ante los nuevos retos y problemas surgidos a raíz de los profundos cambios experimentados en la sociedad actual del trabajo y la necesidad de dar respuestas adecuadas a los mismos, nace un interés especial sobre la indagación de la idea de la justicia social y sus implicaciones prácticas en las relaciones laborales. Esta concepción previa de justicia comporta la aplicación al Derecho del trabajo -y a otras disciplinas afines- del enfoque relacional propio de la Sociología. En dichas investigaciones, que se abordan en un contexto interdisciplinar, experimentan un especial protagonismo, la Sociología, la Economía, la Filosofía, en relación continua y directa con el Derecho. Desde estos planteamientos iniciales, nuestro estudio se ha centrado en la aplicación del enfoque de justicia relacional, como metodología de análisis que, aplicada en el contexto actual de las relaciones de trabajo, se muestra como una herramienta eficaz que podrá favorecer su comprensión y alcance, con especial atención a las situaciones de desigualdad y/o discriminación.

\footnotetext{
${ }^{96}$ Entiéndase que esta proposición también es válida para aquellos supuestos en los que la subordinación o sometimiento se presentan en un grado menor.

${ }^{97}$ Conforme a esta hipótesis y conectando con la Teoría de la justicia propuesta por John RAWLS, en la que se plantea una reciprocidad entre individuos aproximadamente iguales; debemos advertir que, a pesar de ello, existe también un intento, por parte de este autor, en recurrir a "ciertos expedientes", como por ejemplo el "velo de la ignorancia". Vid. RAWLS, J. (1971): A theory of justice, Cambridge (Estados Unidos): Harvard University Press, págs. 32 y 412-413. También y sobre este mismo tema, puede consultarse en HABERMAS, J. y RAWLS, J. (1998): Debate sobre el liberalismo político, Barcelona: Paidós, págs. 75 y ss. Por otra parte, se aprecia en la obra de RAWLS un intento de recurrir a ciertos expedientes, que han sido calificados por MÁRQUEZ PRIETO como un "modo de promover la solidaridad". Vid. MÁRQUEZ PRIETO, A. (2017): "Justicia relacional: enfoque línea y método"...op. cit., pág. 173. Al hilo de lo expuesto, también la autora estadounidense Martha NUSSBAUM ha expresado de forma muy clara la necesidad de encontrar "expedientes de inclusión" que atiendan y respondan a necesidades concretas, socialmente estructuradas, de tal forma que se pueda alcanzar la inclusión social de aquellas personas no incluidas desde una perspectiva de simetría social en la relación de interdependencia. Vid. NUSSBAUM, M. (2002): Giustizia sociale e dignità umana. Da individui a persone...op. cit., p. 111. ${ }^{98}$ Vid. MÁRQUEZ PRIETO, A. (2017): “Justicia relacional: enfoque línea y método"...op. cit., págs. 172173.
} 
Del análisis de las influencias doctrinales históricas, como contribución sustancial a la configuración del enfoque de justicia relacional, conviene destacar la realizada por el economista napolitano del siglo XVIII Antonio GENOVESI y autor de la obra Lezioni di economia civile. Este autor, contemporáneo de Adam SMITH, compartió con él la crítica del mundo feudal y la creencia de que el mercado contribuiría a la construcción de un mundo más igualitario y más libre. Sin embargo, mientras aquel tenía una visión pesimista del hombre basada en el individualismo de intereses, GENOVESI afirmaba que la persona era el equilibrio de dos fuerzas: las de interés para yo y la solidaridad social; el sujeto aparece como una realidad relacional hecha para la reciprocidad. De ahí su idea del mercado como "asistencia mutua". No obstante, fueron las ideas del economista inglés las que calaron con gran aceptación en la sociedad de aquella época. Ahora bien, no se puede obviar que la concepción de la economía por GENOVESI fuera también una referencia a seguir, aunque de forma localizada y minoritaria. Un ejemplo de esta influencia -desconocida y casi inédita en las investigaciones- va a tener lugar en España a cargo del jurista valenciano Bernardo Joaquín DANVILA y VILLARRASA.

Indagar sobre la esencia misma del enfoque relacional, es decir, el porqué de la justicia relacional, implica analizar el contenido -o vacío- de justicia existente en la relación interpersonal, en las diversas dimensiones de las relaciones sociales. Además, debe subrayarse que la justificación de la razón de ser o el porqué de la justicia relacional encuentra su origen en la separación entre el Derecho y la idea de justicia -que va a suceder al finalizar la Edad Moderna-. A su vez, este hito histórico -provocado por el desbordamiento de la idea moderna de justicia- va a requerir que para poder superar este problema se tenga que abordar esta nueva idea de justicia, no como fundamento, sino como resultado. Respecto a la configuración del enfoque de justicia relacional, se distinguen en su ordenación estructural tres dimensiones: reciprocidad, institucionalidad y socialidad. Desde esta triple perspectiva, y superando el análisis unidimensional basado exclusivamente en la aplicación estricta de la norma jurídica -institucionalidad-, se considera fundamental la dimensión del trato o comportamiento recíproco -reciprocidad-, así como, el respeto a determinados valores que fortalecen la confianza en las relaciones laborales -socialidad-.

Por otra parte, de la relación se podrá derivar alguna situación que lleve implícita la ausencia de justicia y, que a su vez, habrá de conectarse con el vacío relacional, de manera que, mediante el análisis de estos vacíos de justicia, se podrá indagar sobre las causas que han impedido que dicha justicia relacional se pudiera desarrollar. En este sentido, la falta de justicia se produce en situaciones en que no existe una verdadera justicia relacional, por ello los vacíos de justicia son desequilibrios que se manifiestan por un déficit de adaptación de la relacionalidad a la reciprocidad o al contrario, por un déficit de la reciprocidad con respecto a la relacionalidad. No obstante, en las relaciones de intercambio entre lo empresarial y lo personal constituye un entrelazamiento en el que el eje de la reciprocidad cobra un protagonismo destacado que hace que esta dimensión asuma la iniciativa.

Respecto a las situaciones de discriminación y/o desigualdad en las que se encuentran determinados colectivos de personas trabajadoras que, por diversas razones -discapacidad, edad, sexo, etc.-, sufren en relación al resto de los trabajadores, se observa la necesidad de una actuación que libere dicho sometimiento, bien sea de forma autónoma o de forma heterónoma, buscando la ineludible armonización de la dependencia con la interdependencia. Es decir, se deberá actuar mediante la puesta en práctica del "expediente de inclusión", como programa previo imprescindible, de tal forma que este mecanismo, propio del enfoque de justicia relacional, corrija la asimetría social y, de esta 
manera, pueda restablecer y facilitar el buen funcionamiento de la interdependencia recíproca. Si bien, conviene precisar que será la dimensión de la institucionalidad la que ha de asumir el liderazgo necesario que corrija los desequilibrios existentes; promoviendo, de esta forma, la inclusión social de los sujetos no incluidos en la relación de interdependencia, en condiciones de simetría social.

Sin embargo, desde el enfoque de justicia relacional no es compatible la realización de un tratamiento jurídico protector frente a la discriminación o desigualdad de estas personas trabajadoras de forma fragmentada o diseccionada. Esta técnica llevaría implícita una doble consideración: la de la regulación jurídica de los trabajadores en general y la de aquellos que tienen especiales necesidades de protección. Por nuestra parte, y desde el enfoque de justicia relacional -como propuesta de lege ferenda-, se sostiene que es mucho más adecuada una regulación unitaria basada en la visión integral de la relación laboral como relación social, pretendiendo el Derecho del Trabajo la inclusión del trabajador en un conjunto de relaciones sociales y en términos de justicia. Siendo esa misma finalidad, unitaria y esencial, la que ha de jugar a favor de las personas trabajadoras en situaciones de discriminación y/o desigualdad.

\section{Bibliografía.}

- ARRIGO, G. (2004): "La implicación de los trabajadores en la sociedad europea", Revista del Ministerio de Trabajo y Asuntos Sociales. Derecho social Internacional y Comunitario, núm. 52: págs.13-29.

- BAGGIO, A. M. (2006): Il principio dimenticato. La fraternità nella rifessione politologica contemporánea, Roma (Italia): Città Nuova.

- BAGGIO, A. M. (2012): "La fraternidad como categoría política”, en BAGGIO, A. M., COSSEDDU, A. y MÁRQUEZ PRIETO, A. (coord.). Fraternidad y justicia, Granada: Comares.

- BRUNI, L. (2005): "Hic Sunt Leones: Social Relations As Unexplored Territory in the Economic Tradition", en GUY, B. y SUGDEN, R. (eds.) Economics and Social Interactions, Cambridge (Reino Unido): Cambridge University Press.

- BRUNI, L. (2006): Reciprocità. Dinamiche di cooperazione, economia e società civile, Milán (Italia): Bruno Mondadori.

- BRUNI, L. (2006): Civil Hapiness: Economics and Human Flourishing in Historical Perpective, Londres (Reino Unido) y Nueva York (Estados Unidos): Routledge.

- BRUNI, L. (2010): L'ethos dell merecato. Un'introduzione ai fondamenti antropologici dell'economia, Milán-Turín (Italia): Bruno Mondadori.

- BRUNI, L. (2012): Le nuove virtù del mercato nell'era dei beni comuni, Roma (Italia): Città Nuova. 
- BRUNI, L. y ZAMAGNI, S. (2013): “Introduzione”, en GENOVESI, A.: Lezioni di economía civile, Milán (Italia): Vita e Pensiero, Francesca Dal Degan, págs. VIIXXII.

- CAMPOY CERVERA, I. (2007): Los derechos de las personas con discapacidad. Perspectivas sociales, políticas, jurídicas y filosóficas, Madrid: Dykinson.

- CATALANO, A. y MALANDRINI, S. (2006): "Costo del lavoro e nuovi modelli organizzativi”, en MALANDRINI, S. y RUSSO, A.: Lo sviluppo del 'capitale umano' tra innovazione organizzativa e tecniche di fidelizzazione, Milano (Italia): Giuffré Editore.

- CERVERA FERRI, P. (S/F): "Bernardo Joaquín Danvila y Villarrasa”, en VV. AA. Real Academia de la Historia. DBE, págs.. s/n. Disponible en:

http://dbe.rah.es/biografias/21094/bernardo-joaquin-danvila-y-villarrasa.

- DANVILA Y VILLARRASA, B. J. (2008): Lecciones de Economía Civil o de el Comercio. Estudio introductorio y edición anotada por Pablo Cervera Ferri (MDCCLXXIX), Zaragoza: Institución "Fernando el Católico"- Biblioteca Ernest Lluch de Economistas Aragoneses 10.

- DONATI, P. (1986): Introduzione alla sociología relazionale, Milán (Italia): Franco Angeli ( $2^{\mathrm{a}}$ ed.).

- DONATI, P. (2002): “Ciudadanía y Sociedad Civil: dos paradigmas (ciudadanía lib/lab y ciudadanía societaria)”, Reis, núm. 98: págs. 37-64.

- DONATI, P. (2005): "Quale conciliazione tra familia e laboro? La prospettiva relazionale", en DONATI, P.: Famiglia e lavoro: dal conflitto a nuove sinergie, Milán (Italia): Franco Angeli.

- DONATI, P. (2006): Repensar la sociedad, Madrid: Ediciones Internacionales Universitarias.

- DONATI, P. (2013): Sociologia relazionale. Come cambiare la società, Brescia (Italia): Editrice La Scuola.

- DONATI, P. y CALVO, P. (2014): "New Insights into Relational Goods”, Recrea. Revista de Pensament i Anàlisi, núm. 14: págs. 7-17.

- FELBER, C. (2012): La economía del bien común, Bilbao: Deusto.

- GENOVESI, A. (2013): Lezioni di economia civile, Milán (Italia): Vita e Pensiero, Francesca Dal Degan.

- HABERMAS, J. (1998): Escritos sobre moralidad y eticidad. Barcelona: Paidós Ibérica.

- HABERMAS, J. (2010): Facticidad y Validez ( $6^{a}$ ed.), Madrid: Trotta editorial. 
- HABERMAS, J. y RAWLS, J. (1998): Debate sobre el liberalismo político, Barcelona: Paidós.

- HEILBRONER, R. (S/F): Adam Smith. Scottish Philosopher, en Encyclopaedia Britannica. Disponible en: https://www.britannica.com/biography/Adam-Smith.

- MÁRQUEZ PRIETO, A. (2008): Repensar la justicia social. Enfoque relacional, teoría de juegos y relaciones laborales en la empresa, Cizur Menor (Navarra): Aranzadi -Thomson Reuters.

- MÁRQUEZ PRIETO, A. (2012): “Justicia relacional y fraternidad”, en BAGGIO, A. M., COSSEDDU, A. y MÁRQUEZ PRIETO, A. (coord.). Fraternidad y justicia. Granada: Comares.

- MÁRQUEZ PRIETO, A. (2014): "La Justicia Relacional como círculo virtuoso", Recrea, Revista de Pensament i Anàlisi, núm. 14: págs. 117-143.

- MÁRQUEZ PRIETO, A. (2015): "La relación laboral como relación social (justicia relacional y socialidad común)", Revista Centro de Estudios Financieros, núm. 382: págs. 13-42.

- MÁRQUEZ PRIETO, A. (2017): “Justicia relacional: enfoque línea y método”, en MÁRQUEZ PRIETO, A. (Coord.) Justicia relacional y principio de fraternidad, Cizur Menor (Navarra): Aranzadi - Thomson Reuters, págs. 145-215.

- MÁRQUEZ PRIETO, A. (2017): "Una investigación en equipo sobre justicia relacional y principio de fraternidad", en MÁRQUEZ PRIETO, A. (Coord.), Justicia relacional y principio de fraternidad, Cizur Menor (Navarra): Aranzadi - Thomson Reuters, págs. 17-28.

- MÁRQUEZ PRIETO, A. (2017): "La nueva Ley andaluza de Derechos y Atención a las personas con discapacidad", en XIII Congreso jurídico de la abogacía ICA Málaga: celebrado el 5 y 6 de octubre de 2017. Marbella (Málaga): Ilustre Colegio de Abogados de Málaga.

- MONTEIRO FERNANDES, A (2006): "L'effettività nel Dirirtto del lavoro: il caso portoghese”, Revista Italiana di Diritto del lavoro, núm. 1: págs. 7-19.

- NUSSBAUM, M. (2002): Giustizia sociale e dignità umana. Da individui a persone, Bolonia (Italia): Il Mulino.

- RAWLS, J. (1971): A theory of justice. Cambridge (Estados Unidos): Harvard University Press.

- SAVIGNY, F. C. (2005): Tratado de la posesión. MONEREO PÉREZ, J. L. (dir.), Granada: Comares.

- SMITH, A. (2002): The Theory of Moral Sentiments (1 ${ }^{a}$ ed. 1759), Cambridge (Reino Unido): Cambridge University Press. 
- SMITH, A. (2008): An Inquiry into the Nature and Causes of the Wealth of Nations: A Selected Edition, en SUTHERLAND, K (ed.). Oxford (Reino Unido): Oxford Paperbacks.

- TEUBNER, G. (2005): La cultura del diritto nell'epoca della globalizzazione. L'emergere delle constituzioni civilli, Roma (Italia): Armando Editore.

- TREU, T. (1999): "Sviluppare la competitività e la giustizia sociales: le relazioni tra istituzioni e parti sociali”, en VV. AA. Studi sul lavoro. Scritti in onore de Gino Giugni (Tomo II), Bari (Italia): Cacucci.

- VALLESPÍN, F. (1998): "Introducción. Una disputa de familia: el debate RawlsHabermas”, en HABERMAS, J. y RAWLS, J. Debate sobre el liberalismo politico, Barcelona: Paidós.

- VELARDE LIZAMA, V. (2012): "Los modelos de la discapacidad: un recorrido histórico", Revista Empresa y Humanismo, vol. XV, núm. 1, págs. 115-136.

- VICTORIA MALDONADO, J. A. (2013): "El modelo social de la discapacidad: una cuestión de derechos humanos", Boletín Mexicano de Derecho Comparado, núm. 138, págs. 1093-1109.

- ZAMAGNI, S. (2012): Por una economía del bien común, Madrid: Ciudad Nueva.

- ZAMAGNI, S. (2012): "Bene comune e fraternità. Il contributo italiano alla storia del Pensiero", en Treccani.it. L'enciclopedia italiana. Economía. Disponible en: http://www.treccani.it. 